\title{
Conceito de autoria como intermédio para noções sobre arte e indústria
}

\section{Gustavo Henrique Ferreira Bittencourt}

Doutor; Universidade Federal do Rio Grande do Norte , Natal, RN, Brasil. gustavohfbitt@gmail.com

\section{Josimey Costa da Silva}

Doutora; Universidade Federal do Rio Grande do Norte, Natal, RN, Brasil. josimeycosta@gmail.com

\section{Resumo}

$\mathrm{O}$ artigo discute o conceito de autoria no cinema como fonte originária de reverberação de valores que incidem nos significados relacionados às noções sobre arte e indústria. Esta revisão crítica e histórica tem a intenção de interpretar a repercussão social da função simbólica da noção de autoria mediante marcas de renomados diretores, com observações sobre os efeitos desta distinção para o comércio do cinema global. Assume-se, ainda, um ponto de inflexão sobre o conceito de star system, deslocando a perspectiva dos atores e atrizes como estrelas para pôr em foco a condição de celebridade do diretor considerado autor como representação artística na história cultural do cinema. As inferências do artigo surgem como resultado de uma análise sobre os efeitos da concepção de autoria como marca de produtos cinematográficos.

\section{Palavras-chave}

Cinema. Star system. Autoria. Performance. Marca.

\section{Introdução}

Os principais parâmetros norteadores desta discussão sobre a autoria no cinema como performance que se atrela à indústria do star system e ao comércio de marcas se apoiam em alguns pressupostos. Propomos que o reconhecimento e a própria noção de 
autoria sejam tratados como categoria heurística1, ou seja, como resultante de um processo, em certos aspectos, simplificador, que permite a pesquisadores, críticos, indústria cinematográfica e público a distinção de obras fílmicas por meio de marcas estilísticas. Essa distinção obedece, em parte, a prerrogativas não racionais definidoras de estratégias que utilizam informação parcial com o objetivo de imediatizar as escolhas. A representativa heurística (HOGG; VAUGHAN, 2010) permite decidir com base em probabilidades (similitudes gerais) que a obra pertence a uma determinada categoria e está vinculada a um autor ou autores. Isso acontece como ato inferencial decorrente da atenção sensível, seja do analista especializado, seja do espectador aficcionado, pois assumimos que ambos usam a operação heurística como chave de análise inconsciente. Presumimos que há uma totalidade de capacidades interpretativas que se pode atribuir a quem quer que distinga marcas 2 de autoria em obras fílmicas, uma vez que todos compartilhamos uma cultura e um tempo histórico comuns e que interferem em nossas percepções e valores. Assim, adotamos a formulação mais genérica de uma competência presumida, de um horizonte interpretativo que se aplica a obras cinematográficas autorais e que tem caráter também cultural e social.

0 autor de cinema seria o detentor de um perfil criativo e estético requisitado como recurso heurístico por meio da mobilização da atenção estética geral. Isso permitiria a identificação de sujeitos precisos (individuais, em sua maioria) como criadores da obra (autores). Tal identificação resultaria de uma leitura de gramática textual e de um processo social extra-semântico decorrente da percepção de processos e dinâmicas que regem a concepção de obras autorais no cinema. Estas são ordenadas sob categorias formais e de conteúdo (em bases poéticas ou estéticas), que demonstram certa coerência narrativa e algum tipo determinado de controle sobre os regimes de produção e de fruição das obras. Tanto a dimensão técnico-artística quanto a dimensão social da autoria se associam para gerar possibilidades de visibilidade por parte do mercado de distribuição das obras e de sensibilidade e reconhecimento por parte dos analistas e espectadores.

Há exemplos de diversos diretores de cinema, cujas trajetórias profissionais e imagens públicas corroboram nossa proposta. Entretanto, enfocaremos um caso singular como representativo desse conjunto de diretores, que, por características comuns em sua trajetória profissional/artística e sua repercussão midiática, podem ser categorizados como

\footnotetext{
${ }^{1}$ No sentido proposto no artigo de Picado e Souza (2018).

2 Nesta discussão, a noção de marcas de autoria conjuga o reconhecimento de sinais de expressividade artística (estilística/poética) de autores de cinema observada por Steven Neale (2002) e David Bordwell (2008), a uma marcaassinatura (CORRIGAN 2003; ELSAESSER 2012) de rótulo comercial como resultante da indústria cinematográfica, que se aproxima da ideia de uma marca/branding (GRAY, 2010); no sentido da publicidade de produtos e empresas.
} 
diretores-autores-estrelas de cinema. Exploramos aspectos da relação complexa entre obra e autoria como performance nas mídias, estabelecendo uma associação disso com os festivais internacionais e o cinema de arte por meio dos seus diretores como integrantes do star system. Elegemos o diretor Lars von Trier pelos seguintes motivos: apresenta um conjunto de obra delineado e uma originalidade criativa correspondente a um perfil de autor; sua "poética de restrição criativa" (ELSAESSER, 2016, p. 35) é considerada marca autoral, uma forma de explorar jogos metalinguísticos em seus filmes, dentre outras questões ligadas à vida pessoal (GRODAL, 2005). Sua trajetória coincide com um plano estratégico traçado entre a construção de sua imagem como personagem e a polêmica envolvendo aspectos de produção e divulgação dos seus filmes; as controvérsias que suscita e que são ampliadas pelas mídias jornalísticas e do entretenimento nos permitem formular articulações entre personalidade e obra, estrelato e vida polêmica das celebridades.

Debatemos a percepção da marca e imagem3 do diretor considerado autor mediante uma revisão histórica da dinâmica cultural estabelecida entre os Estados Unidos e a Europa por entendermos que o cineasta tem papel considerável na história cultural do cinema. Assim, buscamos problematizar a figura do autor/diretor como celebridade componente de um star system (MORIN, 1989; DYER, 1998) em associação à proposição de uma performance de autoria (SAYAD, 2013) com o objetivo de investigar a id entificação do cineasta como estrela cinematográfica que se consagra como marca. 0 autor de cinema é visto como princípio que estimula unidade e coerência na interpretação de obras e como elemento que agrega valor cultural a produtos, por reforçar a dinâmica da autoria como rótulo (CORRIGAN, 2003; ELSAESSER, 2012) ao se transformar em um fetiche que ganha a forma de commodity (HODSDON, 2017, p. 304) na promoção dos filmes.

\section{Valor de culto e de troca}

Arte industrial originada de desenvolvimentos técnico-científicos da modernidade, o cinema atual depende tanto de equipamentos de alta tecnologia quanto de estratégias de vendas sofisticadas para a comercialização de seus produtos-obras, em geral de alto custo

\footnotetext{
${ }^{3}$ A concepção de imagem e auto-projeção do cineasta nas mídias apresentada neste artigo é emprestada de Linda Haverty Rugg (2014) que disserta sobre a construção imagética dos autores de cinema, seja em termos de expressão biográfica (caso de Fellini, Truffaut, Bergman) ou de auto-representação tendo como exemplo Woody Allen, como um meio de estimular uma reflexão sobre o "sentido autoral" para identificação do espectador.
} 
financeiro. Tal perspectiva implica em pensar a figura do autor cinematográfico a partir de um conceito definido por uma mitologia repleta de extensões no mundo da cultura cinematográfica em geral, mas também em admiti-lo como dimensão de um negócio. Essa relação remete às origens do cinema de arte europeu e sua contrapartida no cinema popular americano. Ao longo do tempo e mesmo supondo as limitações criativas decorrentes do sistema industrial de produção, o reconhecimento do diretor em função da sua capacidade expressiva é consolidado historicamente em detrimento do esforço efetivo da realização, que é obrigatoriamente coletiva. Esse tensionamento foi estimulado pela crítica nos primeiros anos da Cahiers du Cinéma, quando os filmes americanos passaram a ser vistos com maior seriedade do que os europeus, uma ideia que abalou a ortodoxia intelectual europeia, influenciando todo o imaginário sobre o pensamento cinematográfico constituído desde então.

O autor de cinema é uma noção tão antiga quanto o próprio meio, mas repercutiu mundialmente quando a Política dos Autores se tornou um marco histórico, no que se refere a uma postura cinéfila de atitude crítica surgida nos anos 1950 na Cahiers du Cinéma. 0 manifesto de Alexandre Astruc, $O$ nascimento de uma nova vanguarda: a câmera-caneta de 1948, foi influência para os redatores da Cahiers lançarem a ideia de ser um filme de autor aquele que traz a experiência de uma expressão pessoal. A controvérsia deve-se, sobretudo, à audácia crítica de François Truffaut lançada em 1954 com o título: Uma certa tendência do cinema francês, quando buscou elevar o cinema de gênero americano, popular e comercial, ao estatuto de obra de arte em detrimento do cinema de adaptação literária praticado na França. A crítica que sobressaía a partir das ideias de Truffaut atentava para a autoria quando se detectava sinais de expressão pessoal e consistência no trabalho de um diretor por meio de um estilo ou temática. Tal modelo, entretanto, excede autores hollywoodianos. A primeira geração de redatores da revista (com nomes que se tornariam eles próprios renomados autores como Truffaut e Jean-Luc Godard, dentre outros), enaltecia os diretores como responsáveis pela criatividade no meio, dentro de um sistema produtivo ocasionado pelas tensões entre expressividade artística e tecnologia industrial, pleiteando a entrada do cinema na história da arte (BAECQUE, 2010). 
A formação de um circuito $^{4}$ de festivais de cinema internacionais serviu para propagar indústrias nacionais de cinema reunidas sob o rótulo "cinema europeu" e, assim, estabelecer um contraponto à influência do cinema norte-americano. No lugar da divulgação em massa dos filmes por gêneros e da promoção de atores/atrizes/estrelas cinematográficas seguindo o modelo comercial, o cinema europeu elaborou sua identidade mediante um "paradigma de autonomia" (ELSAESSER, 2005, p. 23), que elege o princípio do autor como unidade para a ideia de cinema nacional (a escolha do autor como representante do país) e cinema de arte (formas estilísticas e parâmetros narrativos que distinguem-se da narrativa clássica de Hollywood, tendo o contexto institucional das salas de exibição para filmes de arte e os festivais internacionais como espaços de legitimação).

A natureza contraditória da indústria cultural $^{5}$ assimilou essa gênese contracultural e não tardou a usar as atribuições de autoria como instrumento publicitário. A assinatura de um diretor singular era e é cada vez mais vendida como produto, servindo como elemento de reconhecimento dos filmes para a audiência. A lógica que rege esta discussão relacionando a noção de autoria ao seu uso também como rótulo promocional é a de que se trata de um fato culturalmente consolidado e, à maneira dos fatos sociais ${ }^{6}$, com poder de influenciar modos de agir, de pensar e de sentir sobre os sujeitos da cultura. A ideia de autoria é reforçada como estratégia para distinção mercadológica por meio do estabelecimento de nichos especializados, tal como a categoria elástica e híbrida do cinema de arte global7 e suas derivações, em filmes indies, cult e world cinema com seu cânone de referências mundiais; os exemplos são Abbas Kiarostami, Lars von Trier, Wong Kar-Wai. Desta forma, assimilamos os desdobramentos da identificação autoral no mercado de

\footnotetext{
${ }^{4}$ O circuito de festivais, como um fenômeno europeu surgido nos anos 1930, pode ser compreendido pelo papel regulador da Federação Internacional da Associação de Produtores de Cinema (FIAPF) para classificação de critérios destinados ao impacto econômico dos festivais internacionais estabelecidos em calendário anual. A indústria cinematográfica global é intermediada por essa estrutura formada por várias empresas que se juntam para garantir e assegurar seus negócios. Ver mais em: http://www.fiapf.org/intfilmfestivals.asp. Acesso em 20/04/2019.

${ }^{5}$ Aqui entendida conforme Morin (1997), ou seja, como o conjunto institucional de que fazem parte os veículos de comunicação social destinados ao entretenimento público, o que inclui filmes e audiovisuais diversos, programas de televisão, sites, jornais, revistas e ainda, anúncios publicitários e músicas voltadas à cultura cinematográfica.

6 Para maior aprofundamento sobre fatos sociais, cf. DURKHEIM, Émile. As regras do método sociológico. São Paulo: Martins Fontes, 1995. [1 $1^{\mathrm{a}}$ pub. 1895]

7 Esta perspectiva corrobora a compreensão do cinema de arte como equivalente à modalidade de tipos diversos da cinematografia de impulso transnacional, inferindo-se que esta terminologia implica reconhecer a relevância histórica e geopolítica da classificação do cinema de arte como uma espécie de moeda contemporânea para pensar sobre um conjunto de filmes que se aproximam em termos estéticos e políticos, compartilhando modos de produção, circulação e recepção, e se encaixam no chamado cinema de autor e no âmbito do circuito de festivais. (GALT; SCHOONOVER, 2010).
} 
produtos cinematográficos, que se expandem com as tecnologias atuais dos DVD's ao streaming 8

\section{Autoria e noções sobre arte e indústria}

A definição de autoria implica a responsabilidade da criação mediante um nome no âmbito legal e institucional com a função de qualificar uma produção artística, científica, técnica ou filosófica, definindo a condição de autenticidade e referência para determinada obra. Isso se relaciona à ideia de autorismo que, para Corrigan (2003) é um fundamento do pós-guerra que emerge como razão para enaltecer o cinema por meio da escolha do diretor/autor como único criador do filme. Isto implica dizer que o autor de cinema é motivo de autenticidade e expressão pessoal, e serve como juízo para valorizar um produto artístico de origem industrial dependente de esforço coletivo. 0 ideário em torno do autorismo, embora sem consistência e estabilidade como teoria, vem se desenvolvendo como estímulo para empregar variados princípios teóricos-analíticos (em noções gerais sobre o estilo e mise-en-scène, ou acerca de temas que interpretam uma visão de mundo) para falar sobre os filmes e cineastas. A ideia é também relacionada às mudanças e oportunidades tecnológicas do cinema, com suas necessidades industriais e estratégias de mercado.

A ideia de autorismo tem especial relevância em muitas análises fílmicas, que identificam o signo autoral em variadas circunstâncias, distinguindo marca/assinatura com propósitos diversos em formulações que perpassam as obras de muitos teóricos e pesquisadores que discutem o tema da autoria no cinema (ELSAESSER, 2016; HODSDON, 2017). Tal perspectiva está alinhada à concepção do cinema de arte como instituição (NEALE, 2002; BAUMANN, 2007; ANDREWS, 2014), pois legitima noções de autoria como marca e sinal de reconhecimento para os filmes que circulam no circuito de festivais ${ }^{9}$ internacionais, que se especializaram nesse campo.

Algumas condições marcaram a teorização sobre a institucionalização do cinema de arte como categoria definida no imediato pós-guerra: (1) mudanças nos modos de

\footnotetext{
${ }^{8} \mathrm{Um}$ exemplo é o serviço por assinatura $M U B I$ - o nome anterior do streaming era The Auteurs - Os autores. Ver mais em: https://mubi.com. Acesso em 20/04/2019.

9 Nessa direção somos guiados pela narrativa histórica dos festivais como uma rede alternativa de distribuição e promoção do cinema internacional/cinema de arte global (GALT; SCHOONOVER, 2010), modelo consagrado pela repercussão de eventos como Cannes, Berlin e Veneza, por exemplo, que estabeleceram a ideia de um circuito.
} 
produção influenciadas por renovação tecnológica, estética e política; (2) virada econômica em direção às salas de arte, que se desdobraram em espaços para cinema cult e independente; (3) a consequente economia das "produções de prestígio"; (4) as concomitantes transformações em relação à censura nos EUA; (5) as mudanças significativas nos filmes dos anos 1960, com o estímulo do mercado para uma geração de diretores americanos despontarem nos termos da crítica como autores de uma Nova Hollywood, 10 ocasião de resposta impulsionada pelas estratégias dos festivais internacionais, que consagraram o cinema de arte europeu como marca do autor. (BAUMANN, 2007, p. 54).

Andrews (2014) teoriza sobre a noção do cinema de arte como instituição, conjecturando que esta seria uma categoria difusa e expansiva, que envolve desde alguns modos de produção independentes até as estratégias de distribuição e recepção de filmes mediante um conjunto de entidades discursivas que legitimam modos de leituras e práticas cinematográficas. Sua posição reforça a ideia defendida por Neale (2002) no influente artigo Cinema de arte como instituição. Andrews (2014) também discute as dificuldades para elaborar o conceito "cinema de arte", destacando que não se fala em música de arte, pintura de arte ou literatura de arte. Dessa forma, considera incongruente, até contraproducente, insistir em separar legitimação artística e exigências comerciais diante do complexo sistema institucional do cinema contemporâneo:

Nesta definição, o cinema de arte é algo que se desdobra em um evento super-genérico no qual artistas, promotores e audiências tipicamente rejeitam uma ideia desvalorizada e comercializada de filmes como veículos para gêneros. Filmes assinalados por essa categoria geralmente asseguram seu status através de meios institucionais, ou por meio de contextos confiáveis em processos de canonização. 0 complexo resultante tem atormentado acadêmicos com problemas de definição similares àqueles que frequentemente amarguravam os filósofos da arte na tentativa para definir "arte". (ANDREWS, 2014, p. 13, tradução nossa11).

\footnotetext{
10 A expressão Nova Hollywood é um epítome lançado pela crítica para reunir um conjunto heterogêneo de cineastas que despontaram entre as décadas de 1960 e 1970 nos Estados Unidos, considerando o imaginário de "artistas rebeldes contra o sistema", com observações sobre ousadias temáticas, de cunho político e social, e exploração de inovações estéticas. São nomes como Arthur Penn, Dennis Hopper, Robert Altman, Peter Bogdanovich, Martin Scorsese, Francis Ford Coppola, dentre outros; a ideia é pensada como estratégia de mercado que assumiu a condição de oferecer maior liberdade criativa aos diretores como uma contrapartida aos procedimentos europeus de consagração do cinema autoral nos festivais internacionais. (ELSAESSER, 2012).

11 No original: In this definition, art cinema is an unfolding, super-generic event in which artists, promoters, and audiences typically reject a devalued, commercialized idea of the movie as a genre vehicle. Movies assigned to this category often secure their status through institucional means or through context-reliant canonical process. The resulting complexity has plagued artcinema scholars with problems of definition similar to those that once plagued philosophers of art bent on defining "art".
} 
A revisão de aspectos históricos e socioculturais abrangendo a Europa, sobretudo França12, e os Estados Unidos, indicam que, de certo modo, os termos cinema de autor e cinema de arte se interligam e, em certa medida, são intercambiáveis. Os dois termos podem ser referidos como contraponto à rapidez, linearidade narrativa e convenções dos filmes de Hollywood. Um aspecto disso seria a própria variedade de filmes de arte, que transitam entre princípios do realismo (Rossellini) à fantasia (Fellini), de austeridade formal (Dreyer e Bergman) à extravagância visual (Bertolluci), e mesmo pela forma convencional para contar histórias (Truffaut) ou com experimentações narrativas mais radicais (Resnais e Godard); assim,

[...] mesmo quando as marcas de enunciação são heterogêneas, elas tendem à unificação e estabilização dentro do espaço institucional que as lê e localiza de maneira homogeneizada (cada marca servindo igualmente como sinal do autor) na qual mobiliza o sentido de acordo com a commodity-estabelecida pelas práticas de produção, distribuição e exibição (a marca do autor é usada como espécie de marca, para distinguir e vender o produto fílmico). (NEALE, 2002, p. 105, tradução nossa ${ }^{13}$ ).

O autor cinematográfico, ícone para o cinema de arte, evoca o caráter humano que se expressa por meio de um filme como princípio de identificação para o espectador. Em princípio, porém, a ideia de autoria é um valor usado pelos próprios diretores e produtores independentes como contraponto às exigências comerciais. Consideramos que um filme, independente de sua dimensão industrial e coletiva, tem valor agregado quando se destaca como produto criativo do cineasta, profissional que detém domínio sobre os procedimentos cinematográficos, observada a sua individualidade como marca e estilo expressivo. Isso equivale a reconhecer o diretor como artista genuíno. Uma demonstração empírica das implicações dessa noção se encontra nos festivais de cinema internacionais, sejam competitivos ou não. "Da consagração à venda do autor na promoção dos filmes, o circuito

\footnotetext{
12 Nessa exposição, a França pode ser pensada por meio de uma sinédoque, como país para continente, neste caso um substituto do cinema nacional (parte) pelo cinema europeu (todo), por ser exemplo que faz contrapartida à cultura americana em termos de investimento na produção cinematográfica e mediante regime de exceção cultural aos Estados Unidos, etc. Credita-se que os franceses definiram o cinema europeu desde as origens do meio, e continuaram no póssegunda guerra com a influência da Nouvelle Vague, mas, em anos recentes reconhecemos que essa suposição de unidade do cinema europeu alcançou novas facetas. (ELSAESSER, 2005).

${ }^{13}$ No original: [...] even where the marks of enunciation themselves are heterogeneous, they tend to be unified and stabilized within the space of an institution which reads and location them in a homogeneous way (each mark serving equally as the sign of the author) and which mobilises that meaning in accordance with commodity-based practices of production, distribution and exhibition (the mark of the author is used as a kind of brand name, to mark and sell the filmic product).
} 
de festivais transformou-se em habitat para circulação do cinema autoral". (BITTENCOURT, 2018, p. 48).

Apesar de os festivais serem eventos complexos que, em parte, se guiam por agendas políticas da diversidade e do multiculturalismo, não deixam de ser um negócio que envolve vários setores da indústria de massa, com estratégias similares entre eles na promoção dos produtos em mostra. É nesse âmbito que se consagram cânones artísticos, o que ocorre através de mostras competitivas, de premiações e homenagens em retrospectivas, de decisões que legitimam distinções artísticas e agregam valor cultural. Nesse cenário, o cineasta é percebido como interface para representação do cinema, onde reina a função social da autoria (com a presença do autor/filme) e seus efeitos simbólicos (como repercussão de valores estimulados por produtores dos eventos e recepção) mediante estratégias discursivas reforçadas pela programação dos festivais, com destaque para o papel da curadoria, da crítica e do resultado do sistema de premiações, que agregam distinções de reconhecimento, prestígio, etc. Festivais podem ser enquadrados entre aqueles que existem como espaços onde se assistem filmes e lugares facilitadores para venda de filmes, assim como servem de plataformas para lançamento de tendências do cinema mundial por serem espetáculos de grande apelo midiáticos. Como agente promotor do star system cinematográfico, é

[...] evidente que o festival é, antes de tudo, para a opinião que a grande imprensa, os seminários e as revistas especializadas formam ou informam, um encontro de estrelas: vedetes do cinema primeiro, mas também tudo o que participa da vedete: diretores, escritores famosos, pessoas ricas, sultões árabes; e também as aspirantes a vedete: starlets, pin-ups, gênios em potencial. (MORIN, 1989, p. 41).

O "sistema das estrelas" ao qual nos referimos aqui é mais abrangente do que o cenário dos festivais internacionais, mas é nesse circuito que o diretor de cinema protagoniza as atenções da cultura cinéfila e é consagrado publicamente mediante repercussão midiática. Por esses motivos, levamos ainda em consideração que, em termos culturais e econômicos, nada se movimenta hoje sem a marca da celebridade. A biografia de um artista pode ser extrínseca à sua obra, mas parece não ser assim na realidade da cultura cinéfila, pois a vinculação entre vida e obra é algo que é reforçado no imaginário social. 


\section{Star system e o hype da assinatura autoral no mercado cinematográfico}

Segundo Morin (1989), a ideia de star system faz parte das origens da indústria cultural. Entre as décadas de 1910 a 1920 e no decorrer da primeira metade do século, surge como estímulo promocional para o cinema americano. Desde então, a noção reforçou o imaginário sobre a vida das estrelas, criando imagens de desejo e identificação com o público, servindo sobretudo para divulgar produtos cinematográficos mediante a promoção de atrizes e atores. 0 princípio econômico do uso das estrelas para promoção dos filmes se consolidou como fato social e cultural e "o papel das estrelas transcendeu amplamente a tela de cinema" (MORIN, 1989, p. 15). Os atores e atrizes ainda são as personalidades de maior apelo para o público, e também motivo de mais investimento por parte dos estúdios e da economia de atenção midiática lançada pela indústria cultural. Porém, a abrangência do star system é amplificada pelo papel dos diretores, também vistos como estrelas cinematográficas ao se tornarem parte integrante do aparato publicitário e mercadológico de um filme.

Já entre os anos 1965 e 1970, Catherine Deneuve valeu 130 milhões (muito mais que Buñuel, o diretor). Brigitte Bardot atingiu os 150 milhões, [...], enquanto o orçamento de muitos filmes continuava entre 100 e 200 milhões. (MORIN 1989, p. 15).

O significado e as implicações do star system parecem ter sido majoritariamente negligenciados nos estudos sobre o cinema, que muitas vezes os consideram um resumo do que a indústria representa de mais superficial e alienante. Ainda assim, a ideia da celebridade na cultura do cinema em sua dimensão sociocultural mais abrangente é tema de abordagens profundas, como nos estudos de Morin (1989) e Dyer (1998), que versam sobre a produção simbólica e a dinâmica econômica em um amplo sistema cultural. Interessa-nos entender o capital de bens simbólicos criados em torno da autoria, que tem repercussão nas mídias da comunicação social, destacando a construção dessa noção como marca cinematográfica com valor de troca e, muitas vezes, emprego comercial. Parafraseando Dyer (1998), ao olharmos para a estrela de cinema como fenômeno social, admitimos que, independente da ênfase dada à questão (se é do ponto de vista da produção/criação de uma estrela midiática ou como recepção do fenômeno do estrelato), a discussão só pode ser compreendida se nos aprofundarmos nos termos ideológicos que fundamentam uma razão dialética entre produção e consumo. 
A cultura de massas contemporânea implica em consumo rápido de escala global, principalmente quando são produtos de alto custo de produção, que é o caso dos filmes de cinema. O lançamento de filmes de estúdio implica quase sempre em avultado investimento publicitário, a fim de que os lucros justifiquem os custos e isso em geral só pode ser realizado por empresas de enorme capital. A promoção e venda de imagens de artistas do show business, ainda mais quando se trata de autores, atende aos critérios de antropomorfização, sofisticação, exclusividade e distinção como atrativo de produtos que a lógica da publicidade inseriu nas relações sociais em sociedades capitalistas ${ }^{14}$, o que tem se revelado extremamente eficaz e rentável do ponto de vista das dinâmicas econômicas de bens de mercado, sejam simbólicos ou não. Alinhamos esta perspectiva à auto-projeção do diretor de cinema de arte (RUGG, 2014) para uma melhor compreensão da performance de autoria (SAYAD, 2013). Isso nos leva a refletir sobre a imagem do diretor considerado autor na história cultural do cinema.

Lars von Trier é um diretor-autor-estrela que exibe rebeldia em atitudes provocadoras e tem uma biografia ${ }^{15}$ com sinais de infelicidade, depressão, problemas com alcoolismo, drogas, etc., imagem negociada com o público, que assimila esse pathos como narrativa. Desde antes do manifesto Dogma 9516, o dinamarquês tem sido figura notória nos festivais internacionais; sua obra navega entre princípios de um cinema de arte independente e o cinema mainstream. Nessa direção é possível constatar que há, em sua obra, elementos composicionais recorrentes dos filmes de arte, tais como associações líricas-formais, com simbolismos, procedimentos metanarrativos, e autorreferencialidade, dentre outras características. Estes são princípios estilísticos consagrados pelo cinema europeu, mas que, nos filmes do diretor, são misturados às convenções de gêneros do cinema americano, principalmente do melodrama, como é o caso dos filmes que fazem parte da "Trilogia Coração de Ouro" (ELSAESSER, 2016, p. 35), Dançando no escuro"17 (2000) e Dogville (2003), protagonizados respectivamente pela cantora Björk e a estrela Nicole Kidman. Existe uma aproximação entre profissionais do cinema, que desenvolvem uma

\footnotetext{
14 Para maior detalhamento dessa dinâmica, consultar Baudrillard (1981), entre outros.

15 Ainda mais detalhes biográficos sobre von Trier, ver Grodal (2005).

160 movimento que chamou atenção do mercado internacional cinematográfico foi fundado no ano de 1995 em Copenhagem por diretores dinamarqueses liderados por von Trier e Thomas Vinterberg. A ideia central parte do direcionamento a um suposto cinema realista em termos de técnicas fílmicas mais naturais estabelecidas mediante um conjunto de regras que são, na verdade, um apanhado de "negações" que se opõem aos métodos sistematizados nas produções hollywoodianas. Recursos sofisticados estão proibidos, a câmera deve ser usada à mão e não são permitidos efeitos de pós-produção. Ver mais em: http://www.dogme95.dk/interviews/film-according-to-dogma/Acesso em 20/04/2019.

17 Filme vencedor em Cannes da Palma de Ouro, premiação maior do festival.
} 
espécie de sinergia e marca registrada ${ }^{18}$ para o cinema autoral (diretor-autor-estrela) com filmes protagonizados por celebridades midiáticas (atrizes/atores-estrelas). Tal noção é vista também como elemento de estratégia do star system, que influencia o mercado do cinema de arte e é elemento recorrente na história dos filmes lançados no circuito de festivais internacionais ${ }^{19}$.

No entanto, o que parece ser o centro das atenções no cinema do dinamarquês são as polêmicas envolvendo sua personalidade, que servem como estímulo para discutir relações entre vida e obra. Existem acusações contra o cineasta por abuso de poder e misoginia, e o caso mais notório é o de Björk ${ }^{20}$. Outro exemplo de polêmica está na repercussão da declaração feita há alguns anos por Lars von Trier no Festival de Cannes de 2011, na ocasião de lançamento do filme Melancolia ${ }^{21}$ (2011), que o converteu em simpatizante nazista segundo a mídia e persona non grata para o festival, resultando em sua expulsão e banimento por anos.

"Eu entendo Hitler, até simpatizo com ele", disse o realizador, sob os olhares estupefatos das duas estrelas de seu novo longa-metragem, Charlotte Gainsbourg e Kirsten Dunst. Dois anos atrás, Von Trier defendeu com unhas e dentes as ideias por trás de Anticristo, que incluía torturas físicas e uma sequência de mutilação genital explícita. Desta vez, o realizador chegou próximo do suicídio profissional, ao brincar sobre suas supostas inclinações nazistas. (ALMEIDA, 2011).

Nos filmes de von Trier, o uso de imagens violentas e apelo à sexualidade é um artifício comum empregado simultaneamente como provocação artística e estratégia publicitária, consistindo em uma aproximação à transgressão estética e moral do cinema pornográfico. São exemplos na obra de von Trier: Ninfomaníaca, vol. 1 (2013) e vol. 2 (2013), Anticristo (2009) e Os Idiotas (1998). O tema da sexualidade nos festivais e nos filmes sempre fez parte do porvir histórico dos eventos, abordado geralmente com seriedade intelectual e trazendo inovações estéticas, confrontações políticas e discussões filosóficas, de modo a provocar reação da platéia desse nicho de mercado. Frey (2016) trata desta temática em estudo sobre a retórica transgressiva da cultura de cinema de arte atual, o que

\footnotetext{
${ }^{18}$ Rugg (2014) discute essa questão como uma espécie de simbiose de performance que acontece entre atores-atrizes-estrelas e cineastas como parte de uma auto-projeção do diretor de cinema de arte.

19 Para maior aprofundamento da repercussão dos filmes lançados pelo circuito de festivais internacionais entre cineastas considerados autores-estrelas e seus protagonistas, ver Wong (2011).

20 Para mais detalhes, ver reportagem: https://oglobo.globo.com/cultura/filmes/bjork-lista-episodios-em-que-teria-sidoassediada-por-lars-von-trier-21955880 Acesso em 20/04/2019.

${ }^{21}$ Apesar da expulsão do diretor, o filme continuou na competição da mostra principal, levando o prêmio de melhor atriz para Kirsten Dunst.
} 
descreve como um ciclo normalizado de transgressão chancelado pelo circuito. 0 desafio às convenções e o tensionamento são marcas do cinema autoral como forma de distinguir-se do padrão de censura ${ }^{22}$ do modelo de cinema americano influenciado desde a época do Código Hays ${ }^{23}$, em meados do século passado. (FREY, 2016).

Os simbolismos associados às estrelas de cinema extrapolam suas produções próprias e se estendem por um entorno muito mais amplo. Existe uma sinergia entre os produtos culturais, textos (filmes) e os chamados paratextos (textos derivados e periféricos como críticas, entrevistas, informações adicionais e materiais promocionais sobre a produção de filmes etc.). Gray (2010) sugere que os estudos tradicionais têm um enfoque limitado porque se voltam apenas ao objeto em si, neste caso, os próprios filmes. 0 hype da assinatura autoral e seus efeitos mais extensos na cultura compõem, de uma certa forma, o texto fílmico. 0 termo hype refere-se à publicidade exagerada, porém Gray (2010) define hype como produção de sentido relacionado aos inúmeros paratextos. Ou seja, os filmes teriam um impacto de público, crítica e permanência cultural intensificados por seus materiais promocionais como trailers e posters, ou outros discursos públicos da esfera da cultura. Se levarmos em conta que o exame do texto (entendido aqui como filme ou o conjunto da obra) é incompleto sem o contexto de sua produção e recepção, concluímos que, para uma interpretação mais abrangente sobre a noção de autoria cinematográfica, é fundamental a observação dos elementos paratextuais, que reforçam a construção da marca/imagem do cineasta, como proposta que agrega valor aos filmes.

Com esse propósito, elegemos duas imagens que condensam as proposições teóricas que apresentamos até agora. Consideramos que as imagens a seguir, um paratexto, sintetizam o estatuto de estrela conferido ao diretor-autor Lars von Trier, equiparando sua imagem a uma atriz-ícone do star system hollywoodiano:

\footnotetext{
${ }^{22}$ Para maior aprofundamento das questões sobre legislação e censura de filmes distribuídos em alguns países, tendo como referência órgãos nos Estados Unidos (MPAA) e Reino Unido (BBFC), e os processos de interpretação das regulações, ver Frey (2016).

230 código se refere a uma série de normas morais que vigoraram durante as décadas de 1930 a 1960 no sistema de produção hollywoodiano, de forma nem sempre bem-sucedida, com o papel de censurar e coibir a abordagem sobre sexo e violência no cinema. Em 1968, o Código Hays, foi desativado. Com as mudanças sociais, culturais, políticas e econômicas que acompanharam o porvir histórico e atendendo as necessidades da indústria à época, este sistema regulatório fundado pela MPAA (Motion Picture Association of America -Associação de Produtores de Cinema da América) passou a atuar mais como um sistema classificatório destinado à classificação indicativa de faixa etária para os filmes. Ver mais em: https://www.mpaa.org/who-we-are/. Acesso em 20/04/2019.
} 
Figura 1 - Poster do filme A casa que Jack construiu com o diretor Lars Von Trier.

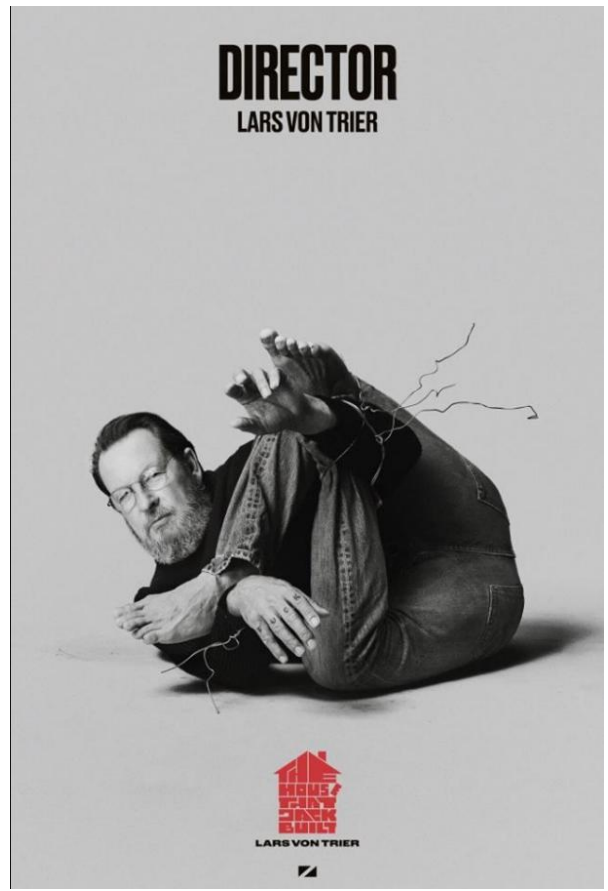

Fonte: The Playlist (2018).

Figura 2 - Poster do filme A casa que Jack construiu com a atriz Uma Thurman.

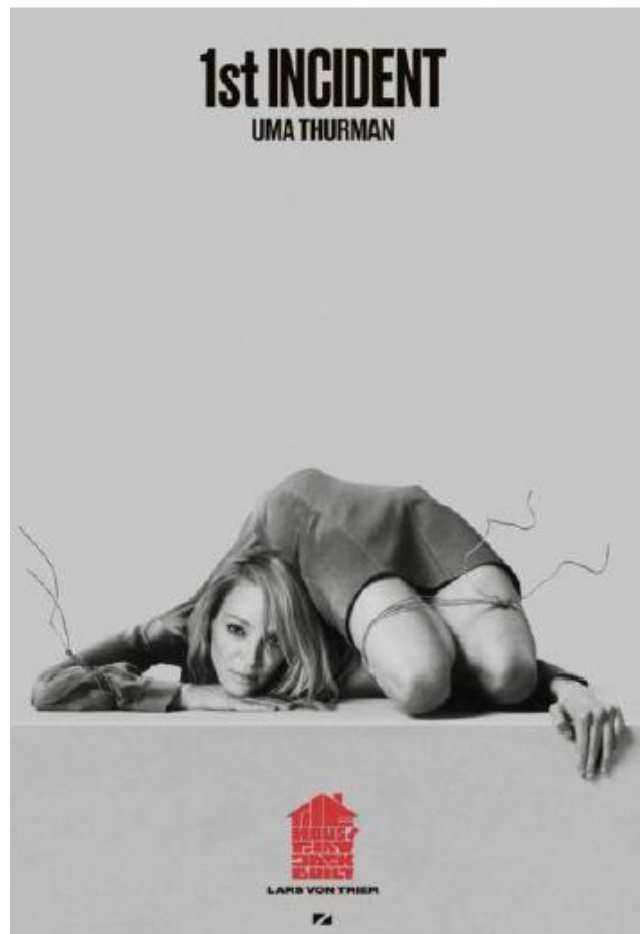

Fonte: The Playlist (2018). 
A imagem do diretor, assim como da atriz Uma Thurman e demais atores numa série de peças promocionais do filme, aparecem em versões estilizadas com corpos contorcidos amarrados por arames. Essas imagens fazem referência aos assassinatos grotescos do serial killer protagonizado por Matt Dillon em A casa que Jack construiu (2018). Destacamos a composição gráfica da peça publicitária a partir do título, disposto como logomarca embaixo dos corpos, sinal de síntese entre a marca-assinatura do diretor e a imagem-marca do filme. Há referências, no decorrer da narrativa, que dialogam com a própria obra do cineasta e respondem a questões envolvendo sua repercussão midiática como autor de cinema. Como escreveu o crítico do The Guardian²4, Mark Kermode (2018): “[...] von Trier tem sugerido que este talvez seja seu último filme, e você pode ler isto como uma espécie de último desejo e testamento, com um ponto principal audaciosamente ridículo".

\section{Considerações finais}

Ao tentar compreender o diretor de cinema como autor, é necessário considerar o seu contexto sócio-cultural como relevante para sua marca autoral. Para isso, é imprescindível uma abordagem que considere "as bordas" do texto fílmico e abarque a compreensão da performance de autoria (SAYAD, 2013). A abordagem da Teoria dos cineastas (PENAFRIA et al 2016, p. 9), na perspectiva de se prestar "atenção ao discurso dos cineastas (sejam verbais ou fílmicos)", e, desta forma, "sistematizar a chegada a estes em busca de consistência reflexiva", poderia ser uma estratégica analítica de aproximação, mas ainda não suficiente para a compreensão que buscamos. Vamos além das leituras de intenções artísticas e pensamentos relacionados aos cineastas e seus filmes para refletir sobre suas atitudes e performances no contexto do comércio cinematográfico. $\mathrm{O}$ conceito de autoria surge como uma classificação simbólica institucionalizada e reconhecida por meio de traços discursivos, que se originam no discurso do cineasta, mas o extrapolam para compor valor de culto em torno do diretor e do cinema como arte. Isso também corresponde ao estímulo de propósitos comerciais, constituído por um mercado de bens simbólicos e grande mobilização de capital.

${ }^{24}$ Trecho da crítica no original: [...] von Trier has suggested that this may be his final film, and you can certainly read it as a sort of last will and testament, with an audaciously ridiculous metaphysical punchline. 
Se nos questionamos sobre o que faz com que um diretor seja considerado autor quando o filme é uma obra coletiva; se nos indagamos sobre o que determina os limites entre uma obra comercial e uma obra artística; se refletimos sobre a visibilidade de determinadas obras de arte em detrimento de outras; se tentamos apreender tudo isso como algo objetivo da realidade, não chegamos a conclusões definitivas. As atribuições de valor e as designações de qualidade, como já afirmamos, são resultado de processos não apenas racionais, de deduções a partir de dados concretos, mas têm componentes emocionais influenciados por experiências sociais com significados e implicações subjetivas. O mundo social, composto pelas esferas econômica, política e cultural, impacta tanto os conceitos quanto as opiniões, tanto as sensibilidades como os acontecimentos. Teorizamos mais ou menos como estudiosos, avaliamos melhor ou pior como críticos, gostamos mais ou menos como público em função de uma atenção seletiva e de escolhas influenciadas pelas informações de que dispomos e pelas tendências captadas em nosso meio. Como já explicitado, essas escolhas, na maior parte das vezes, resultam de um processo heurístico, que nos economiza esforço porque seguimos as tendências.

A noção de autoria é, para nós, uma categoria heurística porque consideramos que uma estrela de cinema (o diretor) é considerado autor com base em similitudes gerais que são grandemente repercutidas pela mídia e o vinculam ao cinema de arte, que, a seu turno, é agrupado nesta categoria com a chancela dos festivais de cinema e da crítica especializada. Essa noção serve como ponto de partida para compreensão da categoria autor no cinema para além de suas intenções artísticas, lidas como inquietações intelectuais dos diretores e como simbolismos, discursos e elementos estilísticos dispostos nos filmes. Tudo isso é também tomado por nós como indicação das preocupações estéticas e políticas dos cineastas analisados sob a perspectiva de auto-expressão, mas reivindicamos que é possível igualmente compreender a categoria como expressão de uma tendência geral com repercussão midiática mais ou menos ampla, que associa fortes traços biográficos e comportamentos individuais a obras fílmicas. Assim chegamos à noção de autoria como performance. Com sua difusão midiática, a performance alça o diretor-autor à posição de celebridade, o faz integrante de um star system, que move toda uma cadeia de significados com valor de troca no mercado de bens simbólicos do cinema comercial. 


\section{Referências}

A CASA que Jack Construiu. Direção: Lars von Trier. Produção: Louise Vesth 2018. (155min.) 1 DVD. Distribuição: Califórnia Filmes. The house that jack built.

ALMEIDA, Carlos Helí de. Declaração nazista de Lars von Trier choca o festival de Cannes. Veja.com, São Paulo, 18 maio 2011.

ANDREWS, David. Theorizing art cinemas: foreign, cult, avant-garde, and beyond. Austin: University of Texas Press, 2014.

ANTICRISTO. Direção: Lars von Trier. Produção: Louise Vesth / Dinamarca/Alemanha/Polônia/França, 2009. (108min.) 1 DVD. Distribuição: Califórnia Filmes. Antichrist.

BAECQUE, Antoine de. Cinefilia: invenção de um olhar, história de uma cultura 1944 -1968. São Paulo: Cosac Naify, 2010.

BAUDRILLARD, Jean. Simulacros e simulações. Tradução: Maria João da Costa Pereira. Lisboa: Relógio D’Água, 1992.

BAUMANN, Shyon. Hollywood highbrow: from entertainment to art. New Jersey: Princeton University Press, 2007.

BITTENCOURT, Gustavo. Tendências do cinema de arte global no circuito de festivais internacionais. In: ALBANO, Sebastião Guilherme; BITTENCOURT, Gustavo; SOUZA, Carla Patrícia Oliveira de Souza. Crítica descentrada para o senso comum: amostragem da reflexão acerca da comunicação contemporânea realizada na UFRN. Curitiba: Appris, 2018.

BORDWELL, David. Poetics of cinema. New York: Routledge, 2008.

CORRIGAN, Timothy. The commerce of auteurism. In: WEXMAN, Virginia Wright. Film and authorship. London: Rutgers University Press, 2003.

DANÇANDO no Escuro. Direção: Lars von Trier. Produção: Vibeke Windelov /

Dinamarca/Alemanha/Bélgica/França/Inglaterra/Estados Unidos, 2000. (140min) 1 DVD.

Distribuição: Versátil Filmes. Dancer in the dark.

DYER, Richard. Stars. London: British Film Institute, 1998.

DOGVILLE. Direção: Lars von Trier. Produção: Vibeke Windelov /

Dinamarca/Alemanha/Suiça/França/Noruega, 2011 (178min.) 1 DVD. Distribuição:

Califórnia Filmes.

ELSAESSER, Thomas. European cinema: face to face with hollywood. Amsterdam: Amsterdam University Press, 2005.

ELSAESSER, Thomas. The persistence of hollywood. New York: Routledge, 2012. 
ELSAESSER, Thomas. The global author: control, creative constrainsts, and performative self-contradiction. In: JEONG, Seung-hoon; SZANIAWSKI, Jeremy (ed.). The global auteur: the politics of authorship in 21 ${ }^{\text {st }}$ century cinema. London: Bloomsbury, 2016.

FREY, Mattias. Extreme cinema: the transgressive rhetoric of today's art film culture. New Jersey: Rutgers University Press, 2016.

GALT, Rosalind; SCHOONOVER, Karl. (ed.). Global art cinema: new theories and histories. New York: Oxford University Press, 2010.

GRAY, Jonathan. Show sold separately: promos, spoilers, and other media paratexts. NY: New York University Press, 2010.

GRODAL, Torben. Frozen flows in von Trier's ouvre. In: GRODAL, Torben; LAURSEN, Iben Thorvin; LARSEN, Bente (ed.). Visual authorship: creativity and intentionality in media. Copenhagen: Museum Tusculanum Press, University of Copenhagen, 2005.

HODSDON, Barret. The elusive auteur: the question of film authorship throughout the age of cinema. North Carolina: McFarland \& Company, Inc, Publishers, 2017.

HOGG, Michael A.; VAUGHAN, Graham M. Psicología Social. Tradução: Marcela Haro Morando et al. 5. ed. Buenos Aires: Médica Panamericana, 2010.

KERMODE, Mark. The house that jack built review: a killer with room for improvement. The Guardian, Reino Unido, 16 dez. 2018.

KOVÁCS, András Bálint. Screening modernism: european art cinema, 1950-1980. Chicago: The University of Chicago Press, 2007.

MELANCOLIA. Direção: Lars von Trier. Produção: Louise Vesth /

Dinamarca/Alemanha/Suiça/França, 2011 (125min.) 1 DVD. Distribuição: Califórnia Filmes Melancholia.

MORIN, Edgar. As estrelas: mito e sedução no cinema. Tradução: Luciano Trigo. Rio de Janeiro: José Olympio Editora, 1989.

MORIN, Edgar. Cultura de massas no século XX: neurose. Tradução: Maura Ribeiro Sardinha. Rio de Janeiro: Forense Universitária, 1997.

NEALE, Steve. Art cinema as institution. In: FOWLER, Catharine. (ed.). The European cinema reader. New York: Routledge, 2002.

NINFOMANÍACA, Vol 1. Direção: Lars von Trier. Produção: Louise Vesth / Dinamarca/Alemanha/Bélgica/França/Inglaterra, 2013 (117min.). 1 DVD. Distribuição: Califórnia Filmes. Nymphomaniac Vol. 1.

NINFOMANÍACA, Vol 2. Direção: Lars von Trier. Produção: Louise Vesth / Dinamarca/Alemanha/Bélgica/França/Inglaterra, 2013 (124min.). Distribuição: Califórnia Filmes Nymphomaniac Vol. 2. 
OS IDIOTAS. Direção: Lars von Trier. Produção: Vinbek Windelov, Dag Alvebert / Dinamarca/Espanha/Suiça/Holanda 1998 (117min.) 1 DVD. Distribuição: Versátil Filmes. Idioterne.

PENAFRIA, Manuela et al. Propostas para a teoria do cinema: teoria dos cineastas. vol. 2. Covilhã: Editora LabCom - IFP, 2016.

PICADO, Benjamin; SOUZA, Maria Carmem Jacob de. Dimensões da autoria e do estilo na ficção seriada televisiva. Matrizes, São Paulo, v. 12, n. 2, p. 53-77, maio/ago. 2018.

RUGG, Linda Haverty. Self-projection: the director's image in art cinema. Minneapolis: University of Minnesota Press, 2014.

SAYAD, Cecilia. Performing authorship: self-inscription and corporeality in the cinema. London: IB Taurus, 2013.

THE PLAYLIST. New, graphic "The house that jack built" posters are examples of Lars von Trier trolling at its finest, 26 september 2018. 2 cartaz, color. Disponível em: https://theplaylist.net/house-jack-built-posters-von-trier-20180926. Acesso em 20/04/2019

WONG, Cindy Hing-Yuk. Film festivals: culture, people and power on the global screen. London: Rutgers University Press, 2011.

\title{
Autorship concept as intermediate for notions about art and cinema industry
}

\begin{abstract}
The article discusses the concept of authorship in cinema as original source of reverberation involved in values that affect the meanings related to notions about art and industry. This critical and historical review intends to interpret the social impact of the symbolic function of authorship notion through renowned directors' brands, with observations about this distinction's effects for global cinema business. A further point of inflection is taken about the concept of star system, shifting perspective from actors and actress as stars, to put in focus the condition of directors considered authors as celebrities and also as artistic representatives in the cultural history of cinema. The inferences of the article are made from an analysis of the effects of authorship conception as a brand of cinematographic products.
\end{abstract}

\section{Keywords}

Cinema. Star system. Authorship. Performance. Brand. 